\title{
REFORMA ADMINISTRATIVA DO PODER EXECUTIVO E AÇÕES DE MODERNIZAÇÃO DA CÂMARA DOS DEPUTADOS
}

\section{PUBLIC MANAGEMENT REFORM AND MODERNIZATION ACTIONS OF THE CHAMBER OF DEPUTIES}

Nilson Matias de Santana*

Resumo: O artigo analisa possíveis relações entre o movimento de reformas administrativas promovidas pelo Poder Executivo no aparelho do Estado, especificamente as mais recentes, e as ações adotadas no processo de modernização do Poder Legislativo, no que se refere à gestão administrativa da Câmara dos Deputados. Os assuntos relacionados ao exercício da função administrativa pelas casas legislativas não têm sido muito abordados nos estudos concernentes ao Poder Legislativo, daí a relevância do tema. O texto traça um breve panorama histórico das principais reformas administrativas conduzidas pelo Poder Executivo, com ênfase na reforma de 1995, que difundiu o modelo de administração gerencial. Por meio de uma pesquisa exploratória, recorre-se à metodologia histórico-descritiva para analisar duas das ações de modernização implementadas pela Câmara dos Deputados, apontando-se possíveis pontos de contato com as diretrizes do movimento que pretendeu reformar o aparelho do Estado. A conclusão é que essas ações revelam vários pontos de contato com as reformas administrativas promovidas pelo Poder Executivo.

Palavras-chaves: Poder Legislativo; Câmara dos Deputados; Modernização Administrativa; Reforma Administrativa.

\begin{abstract}
The paper examines possible relationships between the Brazilian movement of administrative reforms promoted by the Executive Branch in the State apparatus, specifically the most recent, and the actions taken in the process of modernization of the Legislature, in relation to the administrative management of the Chamber of Deputies of Brazil. The issues related to the exercise of administrative function by the legislative houses have not been much discussed in studies related to the Legislature. For this reason, the theme can be considered relevant. The text outlines a brief historical overview of the main administrative reforms

\footnotetext{
* Nilson Matias de Santana, Mestrando Profissional em Poder Legislativo pelo Centro de Formação da Câmara dos Deputados, Especialista em Direito Constitucional pelo Instituto Brasiliense de Direito Público, Especialista em Processo Legislativo pelo Centro de Formação da Câmara dos Deputados, Graduado em Direito pela Universidade Federal de Pernambuco. É Analista Legislativo da Câmara dos Deputados. (nilsonmatias@gmail.com)
} 
conducted by the executive branch, with emphasis on the 1995 reform that has diffused the managerial administrative model. Through an exploratory study by historical-descriptive methodology, the text analyzes two modernization actions implemented by the Chamber of Deputies, aiming to find possible points of contact with the guidelines of the movement that aims to reform the Brazilian state apparatus. The conclusion is that these actions reveal various points of contact with the administrative reforms promoted by the Executive Branch.

Keywords: Legislative Branch; Chamber of Deputies; Administrative Modernization; Administrative Reform.

\section{Introdução}

O Poder Executivo, como responsável pelo exercício precípuo da função administrativa, promoveu, a partir da década de 1930, ações no sentido de modernizar o aparelhamento do Estado, no que se convencionou denominar de reformas administrativas.

Na década de 1990, a reforma do Estado ocupou o centro do protagonismo político como uma resposta ao processo de globalização em curso, que reduziu significativamente a autonomia do Estado para formular e implementar politicas públicas (BRESSER-PEREIRA, 1995). No Brasil, um dos elementos dessa necessidade de reinventar o Estado foi a reforma administrativa, que se tornou tema central em 1995, após a eleição e posse de Fernando Henrique Cardoso na Presidência da República.

Este artigo pretende analisar se essas reformas, especialmente a mais recente, exerceram influência no processo de modernização da gestão administrativa da Câmara dos Deputados. Para isso, por meio de pesquisa exploratória, buscou-se identificar, em duas das principais ações de modernização promovidas pela Câmara dos Deputados, características que revelem, direta ou indiretamente, pontos de contato com as mencionadas reformulações.

Os assuntos relacionados ao exercício da função administrativa pelas casas legislativas não têm sido muito abordados nos estudos concernentes ao Poder Legislativo, daí a relevância do tema.

O texto inicia com um breve panorama das principais reformas promovidas pelo Poder Executivo a partir da década de 1930. Descrevem-se ali as principais características e objetivos dessas alterações. Atenção especial recebeu a chamada reforma gerencial ocorrida em 1995, a partir das diretrizes estabelecidas pelo Plano Diretor para a Reforma do Aparelho do Estado (BRASIL, 1995), concebido durante o primeiro mandato do Presidente Fernando Henrique Cardoso (1995-1998).

Em seguida, abordam-se duas ações de modernização promovidas pela Câmara dos Deputados: a criação da Diretoria de Recursos Humanos e a adoção do Planejamento Estratégico pela Casa. 
$\mathrm{Na}$ última seção, além das considerações finais, são efetuadas sugestões de futuras abordagens.

\section{Breve panorama histórico das reformas administrativas brasileiras}

\subsection{A Era Vargas: a criação do Dasp}

A primeira tentativa de modernização da Administração Pública no Brasil foi a criação do Departamento Administrativo do Serviço Público (Dasp) em 1938, que, conforme esclarece Bariani (2010, p.40), já estava prevista na Constituição de 10 de novembro de 1937:

Art 67. Haverá junto à Presidência da República, organizado por decreto do Presidente, um Departamento Administrativo com as seguintes atribuições: a) o estudo pormenorizado das repartições, departamentos e estabelecimentos públicos, com o fim de determinar, do ponto de vista da economia e eficiência, as modificações a serem feitas na organização dos serviços públicos, sua distribuição e agrupamento, dotações orçamentárias, condições e processos de trabalho, relações de uns com os outros e com o público; (...).(BRASIL, 1937).

Para concretizar o dispositivo anterior, o Dasp foi criado no início do Estado Novo, por meio do Decreto-Lei $n^{\circ}$ 579, de 30 de julho de 1938 (BRASIL, 1938), que elencava suas atribuições, tendo como objetivo principal instituir um modelo de gestão capaz de propiciar racionalidade e excelência produtiva com rigor técnico, associados à impessoalidade e à autonomia. Ainda segundo Bariani, (2010, p. 41), "as influências teóricas dessa proposta estão em autores como Francisco Campos, Max Weber, Henri Fayol”, entre outros.

Wahrlich (1974) assinala que a ênfase na reforma dos meios (atividades de administração geral) foi a característica reformista principal desse período. Segundo a autora, tratava-se de "uma 'reforma modernizadora', inspirada nas melhores fontes disponíveis à época, ou seja, num modelo taylorista/fayoliano/weberiano" (WAHRLICH, 1974, p. 28).

A tarefa do Dasp, nas palavras de Torres, "era exatamente promover a montagem de uma máquina administrativa nos moldes do modelo weberiano, como a afirmação dos princípios do mérito, da centralização, da separação entre o público e o privado, da hierarquia” (TORRES, 2004, p. 147).

Segundo assinala Wahrlich (1983), pode-se até mesmo identificar, já nos discursos da campanha eleitoral do então candidato à Presidência da República, Getúlio Vargas, em 1930, as ideias centrais da reforma administrativa. Embora derrotado nas urnas, o político gaúcho seria conduzido à Presidência por força da Revolução de 1930 (FAUSTO, 2009; LIRA NETO, 2012), levando a cabo o seu intento reformista.

Após a promulgação da Constituição de 1934, o Presidente Vargas encaminhou o projeto de lei que representou a sua primeira medida no tocante à reforma administrativa. Tal projeto resultou na Lei $\mathrm{n}^{\circ} 284$, de 28 de outubro de 1936 (BRASIL, 1936), que aprovou o primeiro plano federal de classificação de cargos, institucionalizando o sistema de mérito para 
acesso ao serviço público.

Percebe-se que, ao menos do ponto de vista da norma, a adoção da meritocracia para ingresso nas fileiras do Estado foi uma tentativa de ruptura com o patrimonialismo até então reinante.

Em sistemas patrimonialistas, sob a ótica dos servidores, têm primazia os interesses dos seus respectivos contratantes, conforme argumentado por Weber (2012).

O termo "patrimonialismo" é oriundo da obra de Weber (2012) e define um tipo específico de dominação, que, por sua vez, é uma modalidade específica de poder (CAMPANTE, 2008). O funcionamento do patrimonialismo na Administração Pública é explicado assim por Costa (2008):

$\mathrm{Na}$ administração pública patrimonialista, o aparelho do Estado funciona como uma extensão do poder soberano, e os seus auxiliares e servidores possuem status de nobreza real. Os cargos são considerados prebendas. A res pvblica não é diferenciada da res principis. (COSTA, 2008, p. 281).

"O conluio entre o poder estatal e o poder privado" (CARVALHO, 2007, p. 25) é o que melhor caracteriza o patrimonialismo. Tal descrição se coaduna com o contexto social da década de 1930 no Brasil, onde o clientelismo, o fisiologismo e a corrupção, viçosos frutos do patrimonialismo, faziam-se presentes em todos os quadrantes da Administração Pública (BARIANI, 2010), o que se apresenta como imenso desafio que o Dasp iria enfrentar.

Bariani avalia que "o Dasp deixou uma marca que contribui para modernizar a administração pública no Brasil" (BARIANI, 2010, p. 60). Sem o Dasp, a crítica ao patrimonialismo teria sido mais difícil e os avanços das décadas seguintes, inexistentes.

Embora atualmente a palavra 'burocracia' tenha adquirido, no senso comum, contornos pejorativos, a adoção da administração pública burocrática, conforme assinala Bresser-Pereira (1999), objetivou a superação da administração patrimonialista. A hierarquia traduzida em unidade de comando, a estrutura piramidal de poder, a rigidez das rotinas, o controle dos processos administrativos visavam à profissionalização da administração para libertá-la das amarras do clientelismo. Daí a necessidade de controles rigorosos, regulações e rotinas severas (BRESSER-PEREIRA, 1999).

\subsection{Período militar: o Decreto-Lei no 200, de 1967}

Durante o regime militar, ocorreu também um processo importante de transformação da Administração Pública. O Decreto-Lei no 200, de 25 de fevereiro de 1967 (BRASIL, 1967), sob a inspiração de Hélio Beltrão e Amaral Peixoto, objetivava modernizar a administração pública mediante a adoção de instrumentos gerenciais de gestão utilizados pela iniciativa privada (TORRES, 2004, p. 153). O decreto estabeleceu, para tanto, cinco princípios fundamentais: planejamento, coordenação, descentralização, delegação de competências e controle. 
Ao traçar o diagnóstico da Reforma Administrativa de 1967, Silva (2010) comenta:

(...) a reforma administrativa de 1967 foi norteada pelo desejo de modernizar o aparelho do Estado e aumentar sua eficiência, adotando, para isso, o padrão de gestão do setor privado. Como afirmou o presidente Castello Branco, em 1965, em mensagem presidencial ao Congresso Nacional, “o propósito é que o setor público possa operar com a eficiência da empresa privada" (...) No contexto da reforma, a gestão privada aparece como antítese da demora, do desperdício, do centralismo, da ausência de controle, dos privilégios e do papelório (SILVA, 2010, p. 63).

Nota-se já aqui, em 1967, a ideia de que a empresa privada é mais eficiente do que a organização pública, questionável premissa que, a partir do final da década de 1990, conforme se verá adiante, motivará a proposta de uma nova reforma no aparelho do Estado.

A reforma administrativa de 1967, de acordo com Silva (2010), nasceu como uma das propostas institucionais da tecnocracia do regime militar na tentativa de racionalizar a administração federal, introduzindo procedimentos gerenciais típicos do setor privado, além de atender, segundo o autor, a demandas provenientes de grupos próximos ao regime, o que explicaria a abertura para a participação do capital privado em sociedades de economia mista.

Devido à natureza do regime, não houve participação ativa da sociedade civil na formulação da reforma administrativa de 1967, que se configurou em um processo da própria burocracia federal.

O planejamento aparece como elemento de racionalidade pragmática, de instrumento para alcance dos objetivos do Estado.

Um dos elementos da descentralização, fixada como um dos princípios no texto do decreto-lei, é a diferenciação entre administração direta e administração indireta. Compõem a primeira, a Presidência da República, os ministérios e os órgãos diretamente subordinados à Presidência. Já a administração indireta é formada por órgãos com autonomia de gestão e personalidade jurídica pública ou privada, constituindo-se na forma de autarquias, empresas públicas e sociedades de economia mista.

O detalhamento da administração pública indireta, com definição de características próprias , segundo Silva (2010), deveu-se à pretensão dos reformadores de permitir que os seus órgãos não se submetessem à rigidez das regras do serviço público federal, de forma a se estabelecer uma descentralização sem subordinação das organizações da administração indireta aos ministérios, dando-lhes maior flexibilidade e autonomia. Dessa forma foi possível, por exemplo, adotar, na administração indireta, o regime trabalhista típico do setor privado, a Consolidação das Leis do Trabalho (CLT). Com isso, os princípios éticos foram enfraquecidos, e o clientelismo voltou a ganhar força na administração pública (SILVA, 2010).

Ao comentar o Decreto-Lei $n^{\circ}$ 200, de 1967, Bresser-Pereira, que seria o artífice da próxima reforma, afirma: 
A reforma iniciada pelo Decreto-Lei $n^{\circ} 200$ foi uma tentativa de superação da rigidez burocrática, podendo ser considerada como um primeiro momento da administração gerencial no Brasil. Toda a ênfase foi dada à descentralização mediante a autonomia da administração indireta, a partir do pressuposto da rigidez da administração direta e da maior eficiência da administração descentralizada. (BRESSER-PEREIRA, 1999, p. 26).

Bresser-Pereira ainda acrescenta que o Decreto-Lei $\mathrm{n}^{\circ} 200$ teria produzido duas consequências indesejáveis: 1) facilitou a sobrevivência de práticas patrimonialistas e fisiológicas, ao permitir a contratação de empregados sem concurso público; 2) deixou de desenvolver carreiras no alto escalão ao não se preocupar com a formação de administradores públicos de alto nível, que eram recrutados, também sem o devido concurso público, das empresas estatais (BRESSER-PEREIRA, 1999).

\subsection{Era FHC - O Plano Diretor para a Reforma do Aparelho do Estado}

Já sob a égide da Constituição de 1988, a principal reforma administrativa ocorreu a partir de meados dos anos 90, e iniciou-se com o movimento denominado de 'administração pública gerencial'. Conforme afirma Ana Paula Paes de Paula, "a reforma gerencial brasileira foi um desdobramento do ajuste estrutural da economia, que teve início com a adesão do Governo Collor às recomendações do Consenso de Washington para a crise latino-americana" (PAES DE PAULA, 2007, p. 125).

O contexto histórico da reforma gerencial é apresentado, em breves linhas, por Christina Andrews:

\footnotetext{
Enquanto o Brasil e outros países latino-americanos mergulhavam na recessão, os países desenvolvidos, à sua maneira, também iniciavam o ajustamento. O crescimento econômico das décadas anteriores nesses países viera ao custo do aumento das taxas de inflação, levando os formuladores de políticas públicas a abraçar a visão crítica do "Estado do Bem-estar Social" e de seu custoso aparato burocrático. Na Europa, a partir do final da década de 1970, a ênfase em políticas sociais promotoras da igualdade social cede terreno para a ênfase em políticas voltadas para a contenção do déficit orçamentário, fazendo emergir em todas as frentes políticas a ideia da eficiência administrativa (ANDREWS, 2010, p. 88).
}

A quase totalidade da literatura acerca do assunto aponta o contexto de crise internacional como indutor da proposta de reformulação do papel do Estado que levou, na década de 1990, vários países a promoverem reformas (ANDREWS, 2010; BENINI, BENINI e NOVAES, 2012; BRESSER-PEREIRA, 1999; PAES DE PAULA, 2007).

Inspirado na experiência de outros países, principalmente da Grã-Bretanha, em 1995, o então Ministro da Administração Federal e Reforma do Estado, Luiz Carlos Bresser Pereira, apresentou o Plano Diretor da Reforma do Aparelho do Estado (PDRAE), que traçava um diagnóstico da burocracia estatal e apontava os objetivos a serem perseguidos pelo governo e pela sociedade, para prover a administração pública de níveis mais altos de governabilidade e governança (TORRES, 2004, p. 172). 
O aparelho do Estado foi definido como a administração pública em sentido amplo, acepção em que representa a própria estrutura organizacional do Estado, englobando os três poderes (Executivo, Legislativo e Judiciário), nas três esferas federativas (União, Estadosmembros e Municípios) (BRASIL, 1995).

Ao apresentar o PDRAE, o então Presidente da República Fernando Henrique Cardoso esclareceu os objetivos da reforma pretendida:

Este "Plano Diretor" procura criar condições para a reconstrução da administração pública em bases modernas e racionais. No passado, constituiu grande avanço a implementação de uma administração pública formal, baseada em princípios racional-burocráticos, os quais se contrapunham ao patrimonialismo, ao clientelismo, ao nepotismo, vícios estes que ainda persistem e que precisam ser extirpados. Mas o sistema introduzido, ao limitar-se a padrões hierárquicos rígidos e ao concentrar-se no controle dos processos e não dos resultados, revelou-se lento e ineficiente para a magnitude e a complexidade dos desafios que o País passou a enfrentar diante da globalização econômica. (BRASIL, 1995, p. 6).

O plano propunha a adoção no Brasil do modelo gerencial de administração pública, uma vez que o modelo burocrático weberiano era tido como não mais adequado à administração de um Estado moderno.

O PDRAE distinguiu as funções do Estado em três macroáreas de atuação: atividades exclusivas do Estado; serviços sociais e científicos do Estado; produção de bens e serviços para o mercado. A cada uma das áreas de atuação, segundo o PDRAE, corresponde uma forma de propriedade.

A figura 1 apresenta o relacionamento entre as formas de propriedade e de administração e as áreas de atuação do Estado.

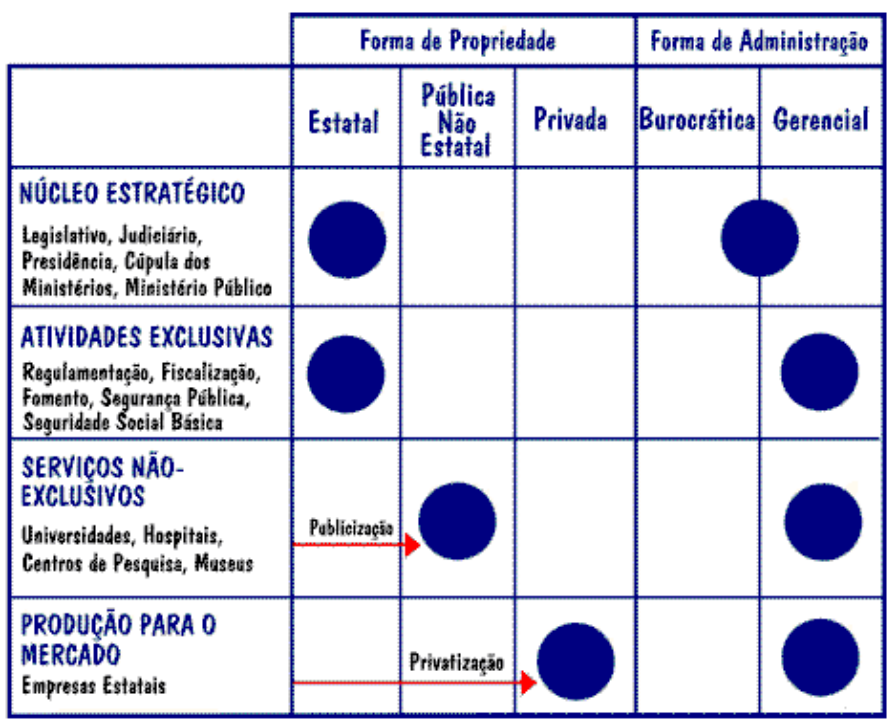

Figura 1: áreas de atuação do Estado

Fonte: PDRAE (BRASIL, 1995, p. 48) 
No NÚCLEO ESTRATÉGICO está o coração do Estado. Segundo o PDRAE, é somente aí que se justifica a permanência do modelo burocrático, por sua efetividade e segurança, embora seja necessário modernizá-lo por meio da adoção de práticas da administração gerencial. Nas demais áreas de atuação, apenas o modelo gerencial puro deve ser adotado.

As ATIVIDADES EXCLUSIVAS englobam aqueles serviços que apenas o Estado pode realizar. Segundo o PDRAE,

\begin{abstract}
São serviços em que se exerce o poder extroverso do Estado - o poder de regulamentar, fiscalizar, fomentar. Como exemplos temos: a cobrança e fiscalização dos impostos, a polícia, a previdência social básica, o serviço de desemprego, a fiscalização do cumprimento de normas sanitárias, o serviço de trânsito, a compra de serviços de saúde pelo Estado, o controle do meio ambiente, o subsídio à educação básica, o serviço de emissão de passaportes, etc. (BRASIL, 1995, p. 41).
\end{abstract}

Os SERVIÇOS NÃO EXCLUSIVOS englobam aquelas atividades em que o Estado atua em conjunto com outras organizações públicas não estatais e privadas. São serviços que envolvem atividades ligadas a direitos fundamentais, como, por exemplo, educação e saúde. O PDRAE cita como exemplos as universidades, os hospitais, os centros de pesquisa e os museus (BRASIL, 1995).

O setor denominado PRODUÇÃO DE BENS E SERVIÇOS PARA O MERCADO equivale ao campo de atuação das empresas. São atividades que, embora permaneçam no aparelho do Estado, regem-se pela lógica de mercado, voltadas para o lucro.

\title{
2.3 A Era Lula: o Programa Nacional de Gestão Pública e Desburocratização -
}

\section{Gespública}

Em janeiro de 2003, Luiz Inácio Lula da Silva tomou posse como Presidente da República. Por ser oriundo de um partido de esquerda, cuja atuação parlamentar se caracterizara por ferrenha oposição às ideias difundidas pelo PRDRAE, havia uma grande expectativa sobre qual seria a postura do novo governo em relação à administração pública.

O tempo demonstrou que os temores de ruptura eram infundados. Conforme assinala Abrúcio (2007, p. 77), “o governo Lula continuou uma série de iniciativas advindas da experiência anterior da modernização do Estado brasileiro, particularmente no reforço de algumas carreiras".

Em 2005, é instituído o Programa Nacional de Gestão Pública e Desburocratização Gespública, com a finalidade de contribuir para a melhoria da qualidade dos serviços públicos prestados aos cidadãos e para o aumento da competitividade do País (BRASIL, 2005). O Gespública tem abrangência nacional e se direciona às organizações públicas em geral, sendo aberto a todas as esferas de governo e a todos os poderes. 
O Gespública representa a tentativa de continuidade do modelo gerencial, uma vez que foi instituído a partir da evolução de programas anteriores.

A figura 2 ilustra a evolução que levou ao desenvolvimento do Gespública.

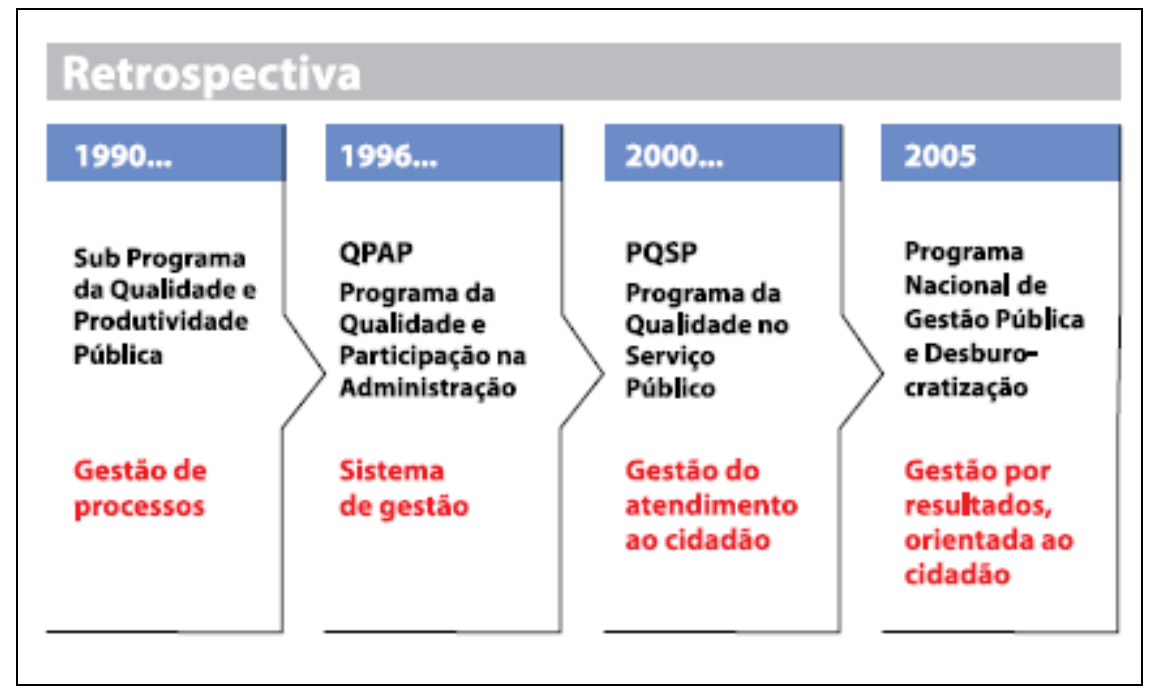

Figura 2 - Marcos na evolução do Gespública.

Fonte: Documento de referência (BRASIL, 2008/2009)

Os quatro marcos mostrados na Figura 2 não representam rupturas e sim incrementos importantes a partir do programa inicial (BRASIL, 2009).

O Documento de Referência 2008/2009 do Gespública esclarece:

O Programa Nacional da Gestão Pública e Desburocratização é um poderoso instrumento de cidadania, conduzindo cidadãos e agentes públicos ao exercício prático de uma administração púbica ética, participativa, descentralizada, promotora do controle social e orientada para resultados, entre outras ações gerenciais. (BRASIL, 2009, p. 9).

O Gespública foi formulado sob a premissa básica de que a gestão pública pode atingir altos níveis de excelência sem deixar de ser pública. A qualidade na gestão deve ser desenvolvida e orientada dentro dos princípios constitucionais da legalidade, da moralidade, da impessoalidade, da publicidade e da eficiência (BRASIL, 2009), que é o traço característico da ação administrativa do Estado, voltado para o interesse público.

Os instrumentos e os conceitos do Gespública não se limitam áreas a específicas (saúde, educação, previdência, fiscalização etc), mas aplicam-se a toda a administração pública e todos os poderes do Estado e esferas federativas (BRASIL, 2009).

O Gespública possui um conjunto de orientações e parâmetros que formam um instrumento para avaliação e melhoria da gestão das instituições que aderiram ao Programa. Essa ferramenta, de natureza gerencial, apresenta todos os critérios e itens de avaliação 
necessários para se aferir o nível de desenvolvimento da gestão de determinada organização pública.

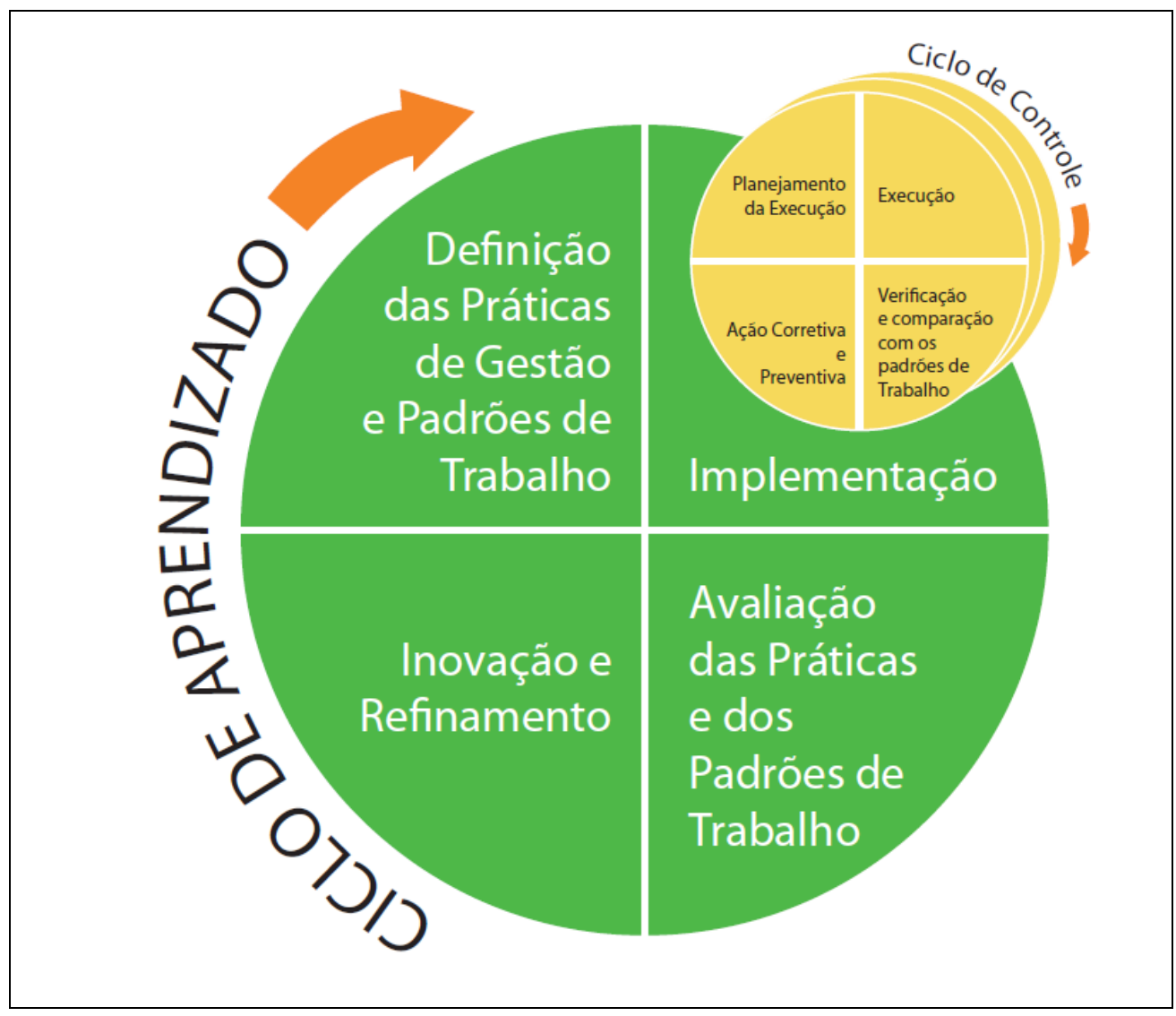

Figura 3 - Diagrama de gestão das práticas do Gespública

Fonte: MPOG (BRASIL, 2010)

Abrúcio (2007) aponta como experiência bem-sucedida no campo da gestão pública no governo Lula duas ações levadas a efeito no âmbito da Federação: o Programa Nacional de Apoio à Modernização da Gestão e do Planejamento dos Estados e do Distrito Federal (Pnage) e o Programa de Modernização do Controle Externo dos Estados e Municípios Brasileiros (Promoex). Tais programas objetivam modernizar a administração pública das instâncias subnacionais, particularmente no nível estadual.

\section{A modernização administrativa na Câmara dos Deputados}

Como órgão do Poder Legislativo e integrante do núcleo estratégico do Estado (conforme indicado na figura 1), a Câmara dos Deputados não foi indiferente aos ventos reformistas que alçaram o modelo gerencial à condição de protagonista na Administração Pública a partir de 1995.

É possível identificar nas ações de modernização administrativa implementadas nos últimos dez anos pela administração da Câmara dos Deputados a influência, ainda que indireta, 
dos paradigmas estabelecidos nas mais recentes reformas administrativas conduzidas pelo Poder

Executivo. Nas seções seguintes, serão abordadas duas dessas ações.

\title{
3.1 A criação da Diretoria de Recursos Humanos (DRH)
}

A estrutura organizacional da Câmara dos Deputados é regida pela Resolução $n^{\circ} 20$, de 30 de novembro de 1971 (BRASIL, 1971). Sofreu várias alterações, embora sem grandes modificações na essência.

Uma modificação relevante nessa estrutura foi a criação, por meio do Ato da Mesa $\mathrm{n}^{\circ}$ 27, de 20 de agosto de 2003 (BRASIL, 2003), da Diretoria de Recursos Humanos. Na justificação no ato está registrado:

\begin{abstract}
Desde a edição da Resolução ${ }^{\circ} 20$, de 1971, notórias são as modificações havidas na sociedade, no Direito Constitucional, no Direito Administrativo, na Ciência da Administração e, consequentemente, na Administração Pública brasileira. Em razão disso, a reestruturação administrativa da Casa faz-se necessária, a fim de adaptá-la à atualidade. Se agora não é possível uma completa reestruturação, ao menos parte dela se toma imperiosa. (BRASIL, 2003, p. 10).
\end{abstract}

Essas notórias modificações anteriormente referidas, principalmente no que se refere à administração pública podem ser identificadas com as ações que, a partir principalmente do PDRAE (BRASIL, 1995), difundiram o modelo gerencial, que já preconizava como prioritária a adoção de uma nova política de recursos humanos, que deveria passar pela profissionalização e valorização do servidor público, a fim de se atender com qualidade aos novos papéis do Estado.

A ideia de valorização do servidor pressupõe, ainda segundo o PDRAE:

(1) criar condições psicossociais necessárias ao fortalecimento do espírito empreendedor do serviço público, conjugada ao comportamento ético e ao desempenho eficiente; (2) reforçar o sentido de missão e o comprometimento do servidor público para com a prestação de serviços de melhor qualidade para o cidadão, e (3) obter maior satisfação do servidor público com o seu trabalho e com sua qualidade de vida. (BRASIL, 1995, 64).

A Diretoria de Recursos Humanos da Câmara dos Deputados tem, desde a sua criação, promovido ações que guardam consonância com os objetivos acima transcritos. A estruturação da diretoria abrange as áreas de saúde, gestão de pessoal e treinamento, que desenvolvem programas voltados para a valorização do servidor.

Em 2006, a Diretoria de Recursos Humanos (DRH) foi introdutora do planejamento estratégico na Câmara dos Deputados, ocasião em que desenvolveu o seu planejamento estratégico setorial, utilizando a metodologia BSC. No final daquele ano, era lançado o Plano de Gestão Estratégica da Área de Recursos Humanos, no qual se apresentou o respectivo Mapa Estratégico Setorial, sendo depois seguida por outros setores da Casa (GUIMARÃES et al, 2012). 


\subsection{A adoção do planejamento estratégico}

Segundo Bergue (2011, p. 423), “a estratégia, como elemento teórico no campo das ciências sociais, desenvolveu-se a partir de meados do século XX, especialmente no período do pós-Segunda Guerra Mundial, sob forte influência das Ciências Econômicas”.

O termo 'estratégia' provém do grego strategia - a arte do general, tendo sido empregada pela primeira vez na língua inglesa em 1688 (WHIPP apud BERGUE, 2011).

O processo de Planejamento Estratégico, iniciado de forma incipiente em 2004, ainda sem a utilização dessa terminologia (o que somente ocorreria formalmente em 2006), estabeleceu como missão da área de apoio técnico administrativo e legislativo "dar suporte à atividade parlamentar, com qualidade e ética, contribuindo para o seu contínuo fortalecimento, aperfeiçoamento e transparência". Como desdobramento, foram estabelecidos os objetivos, as medidas e os recursos necessários para cumprir essa missão.

Mintzberg, Ahlstrand e Lampel (2010) relacionam dez escolas de planejamento estratégico conforme a visão que adotam acerca do processo de formulação de estratégia:

Quadro 1: Escolas de formulação de estratégia

\begin{tabular}{|l|l|}
\hline \multicolumn{1}{|c|}{ ESCOLA } & \multicolumn{1}{c|}{ VISÃO DO PROCESSO DE ESTRATÉGIA } \\
\hline Escola do Design & Formulação de estratégia como um processo de concepção. \\
\hline Escola do Planejamento & Formulação de estratégia como um processo formal. \\
\hline Escola do Posicionamento & Formulação de estratégia como um processo analítico \\
\hline Escola Empreendedora & Formulação de estratégia como um processo visionário \\
\hline Escola Cognitiva & Formulação de estratégia como um processo mental \\
\hline Escola de Aprendizado & Formulação de estratégia como um processo emergente \\
\hline Escola do Poder & Formulação de estratégia como um processo de negociação. \\
\hline Escola Cultural & Formulação de estratégia como um processo coletivo \\
\hline Escola Ambiental & Formulação de estratégia como um processo reativo \\
\hline Escola da Configuração & Formulação de estratégia como um processo de transformação \\
\hline
\end{tabular}

Fonte: Mintzberg, Ahlstrand e Lampel (2010). (itálicos reproduzidos do original).

Segundo Guimarães et alli (2012), o planejamento estratégico na Câmara dos Deputado seguiu um movimento middle-up-down:

Em 2006 a Diretoria de Recursos Humanos (DRH) desenvolveu seu planejamento estratégico setorial, utilizando a metodologia BSC18. Em dezembro do mesmo ano, foi lançado o Plano de Gestão Estratégica da Área de Recursos Humanos, no qual se apresentou o respectivo Mapa Estratégico Setorial. Posteriormente, outros setores o fizeram (setembro de 2007 Secretaria de Comunicação Social; dezembro de 2007 - Secretaria de Controle Interno; outubro de 2008 - Diretoria Legislativa; dezembro de 2008 - Diretoria Administrativa). Esse fato levou Botelho e Melo (2009) a considerarem o processo de gestão estratégica da Câmara como middle-updown ou "estratégia corporativa deduzida". (GUIMARÃES et al, 2012, p. 29) 
O modelo de gestão middle-up-down considera que a gerência intermediária de uma organização é o centro principal da produção de conhecimento mediante um movimento de espiral para cima e para baixo, na estrutura organizacional, que posiciona os gestores intermediários no cruzamento dos fluxos verticais e horizontais de informações (NONAKA; TAKEUCHI, 1997).

O Mapa Estratégico Corporativo da Câmara dos Deputados (Figura 5) foi lançado em abril de 2009.

Percebe-se a explícita adoção do modelo gerencial em ações referentes aos processos internos, tais como: "subsidiar a tomada de decisões por meio de informações e análises tempestivas", "aprimorar a gestão e a disseminação da informação e do conhecimento", "aprimorar continuamente os instrumentos da gestão estratégica", "modernizar a gestão de processos de trabalho".

O Plano Diretor para a Reforma do Aparelho do Estado, ao se referir ao núcleo estratégico - do qual faz parte o Poder Legislativo - apresenta como um dos objetivos "aumentar a efetividade do núcleo estratégico, de forma que os objetivos democraticamente acordados sejam adequada e efetivamente alcançados" (BRASIL, 1995, p. 45). Para isso, propõe modernizar a administração burocrática, que, conforme já ficou registrado acima, ainda é justificável no núcleo estratégico.

Embora não se possa afirmar que a adoção do planejamento estratégico na Câmara dos Deputados tenha sido explicitamente inspirada pelo movimento de implantação do modelo gerencial no Poder Executivo, o mapa estratégico corporativo (Figura 4) revela que a cultura disseminada pelo Plano Diretor para a Reforma do Aparelho do Estado encontrou solo fértil na administração daquela Casa Legislativa. 


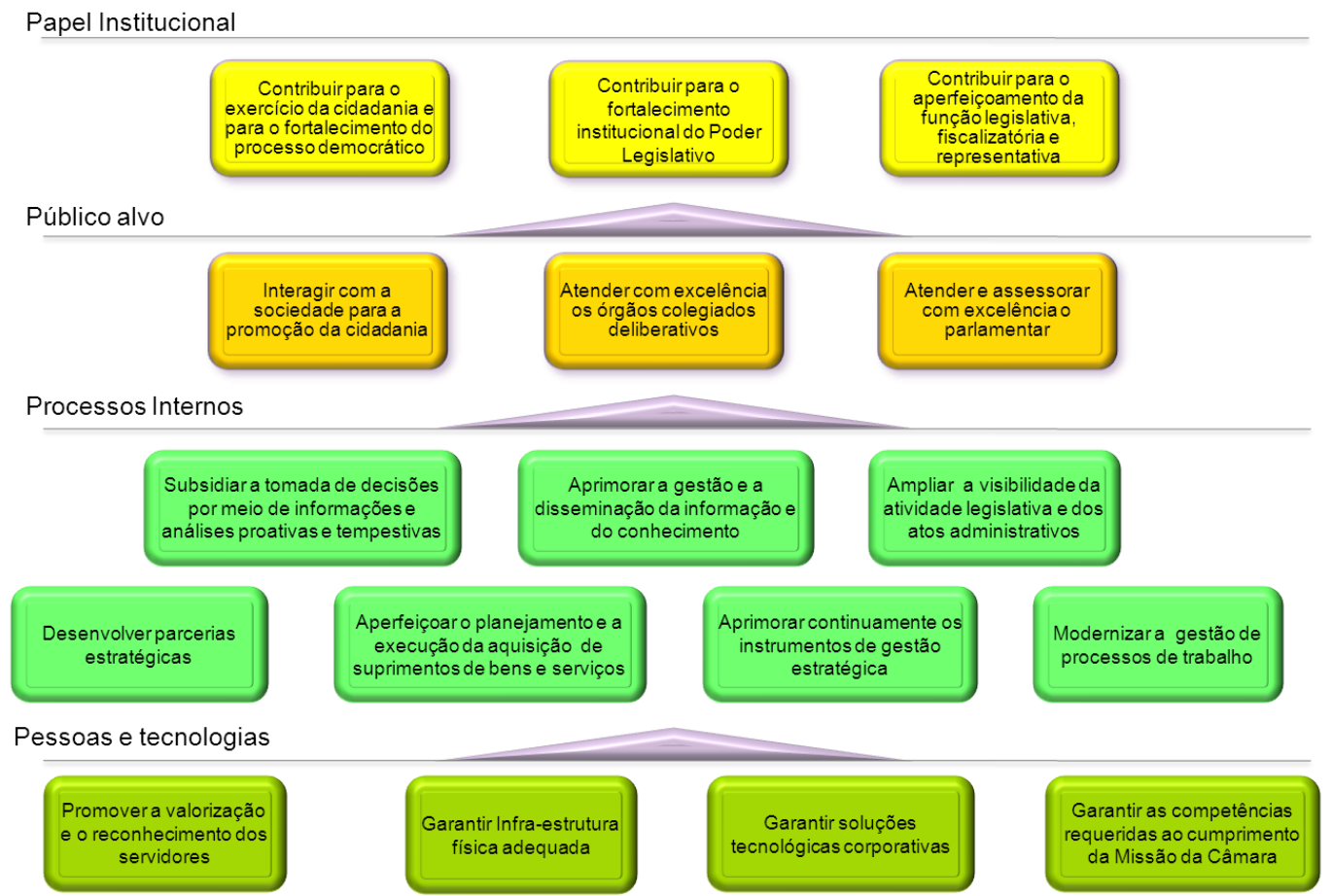

Figura 4: Mapa estratégico corporativo da Câmara dos Deputados.

Fonte: Oliveira (2011).

Até mesmo nas diretrizes estratégicas 2012-2023, referente ao planejamento de longo prazo da Câmara dos Deputados, percebe-se a presença marcante do modelo gerencial. A diretriz 7, que trata da gestão, estabelece:

Linhas de Atuação:

7.1 Aprimorar o processo decisório, a gestão de projetos, de processos e de riscos corporativos, e o uso de indicadores de desempenho;

7.2 Melhorar a gestão e a disseminação de informações internas;

7.3 Assegurar a infraestrutura adequada e continuidade dos serviços;

7.4 Promover uma adequada gestão de pessoas, com ênfase na produtividade, meritocracia e qualidade de vida;

7.5 Melhorar a eficiência administrativa e a utilização dos recursos:

7.6 Instituir serviços comuns ao Parlamento. (BRASIL, 2013)

Essas ações encontram plena correspondência em vários dos conceitos e valores presentes tanto no PDRAE quanto no Gespública, o que parece indicar a mesma concepção de administração gerencial.

\section{Conclusão}

O processo de reforma do aparelho do Estado deve ser considerado em andamento constante. Essa história ainda não acabou. A administração pública brasileira precisa avançar no sentido de superar cada vez mais o patrimonialismo que, infelizmente ainda é bem presente, inclusive no Poder Legislativo.

As ações de modernização da Câmara dos Deputados analisadas - a criação da Diretoria de Recursos Humanos e a implantação do Planejamento Estratégico - apontam vários possíveis 
pontos de contato com as reformas administrativas promovidas pelo Poder Executivo a partir de 1995, sob inspiração do Plano Diretor da Reforma do Aparelho do Estado, assim como alguns dos conceitos e valores do Gespública. Embora seja verdade que, sem um estudo mais aprofundado, não se pode afirmar que essas ações sofreram influência direta do Plano, é também verdade que toda mudança ocorre como resposta ao contexto cultural circundante. Os estreitos limites do presente trabalho exploratório não permitiram a coleta de dados mais consistentes com vistas ao aprofundamento do tema.

O quadro 2 mostra a convergência de conceitos e valores entre os mais recentes programas de reforma administrativo do Poder Executivo e algumas das diretrizes estratégicas da Câmara dos Deputados.

Quadro 2 - Convergência conceitual entre o PDRAE, o Gespública e as Diretrizes Estratégicas da Câmara dos Deputados

\begin{tabular}{|l|l|}
\hline \multicolumn{1}{|c|}{ PDRAE E GESPÚBLICA } & \multicolumn{1}{|c|}{ DIRETRIZES ESTRATÉGICAS 2012-2023 - CÂMARA } \\
DOS DEPUTADOS
\end{tabular}

Fonte: Elaboração própria

Nesse sentido, percebe-se que o modelo gerencial adotado pela Câmara dos Deputados, sob ponto de vista conceitual, está em consonância com os pressupostos dos principais movimentos de modernização da gestão pública.

Há um vasto campo de estudo ainda não desbravado no que se refere à gestão administrativa no Poder Legislativo. Uma possível proposta de pesquisa - transcendendo os objetivos restritos deste artigo - seria investigar com mais profundidade (mediante possível análise documental e entrevistas com atores-chaves dos processos de modernização) se tais convergências são realmente fruto da adoção consciente dos elementos do movimento de reforma do Estado, por meio da influência direta do Poder Executivo, ainda que retardada no tempo, ou se o próprio contexto do Poder Legislativo levou os seus gestores a trilharem o mesmo caminho em direção ao modelo gerencial de forma independente, em um autêntico voo solo. 


\section{Referências}

ABRÚCIO, Fernando Luiz. Trajetória recente da gestão pública brasileira: um balanço crítico e a renovação da agenda de reformas. RAP. Revista Brasileira de Administração Pública, 2007. v. 1, p. 77-87.

ANDREWS, Cristina W. Da década perdida à reforma gerencial: 1980-1998. In:

BARIANI, Edison (org). Administração pública no Brasil: breve história política. São Paulo: Unifesp, 2010. p. 85-118.

BARIANI, Edison. Dasp: entre a norma e o fato. In: ANDREWS, Cristina W.; (org). Administração pública no Brasil: breve história política. São Paulo: Unifesp, 2010. p. 38-62.

BENINI, Édi Augusto; BENINI, Élcio Gustavo; NOVAES, Henrique Tahan. Os grilhões da gestão pública: o processo decisório e as formas contemporâneas de dominação patrimonialista. Cadernos Gestão Social, jan./jun. 2012, v. 3, n. 1, p. 85-100. Disponível em: <http://www.periodicos.adm.ufba.br/index.php/cgs/issue/view/8/showToc>. Acesso em: 21 maio 2013.

BERGUE, Sandro Trescastro. Modelos de gestão em organizações públicas: teorias e tecnologias para análise e transformação organizacional. Caxias do Sul: Educs, 2011.

BRASIL. Ministério do Planejamento, Orçamento e Gestão. Secretaria de Gestão. Programa Nacional de Gestão Pública e Desburocratização - Gespública. Documento de referência 2008/2009. Brasília: MPOG, 2009.

BRASIL. Ministério do Planejamento, Orçamento e Gestão. Secretaria de Gestão. Programa Nacional de Gestão Pública e Desburocratização - Gespública. Instrumento para avaliação da gestão pública - ciclo 2010. Brasília: MPOG, 2010.

BRASIL. Poder Executivo. Plano diretor da reforma do aparelho do Estado. Ministério da Administração Federal e da Reforma do Estado. Brasília, 1995. Disponível em: <http://www.bresserpereira.org.br/Documents/MARE/PlanoDiretor/planodiretor.pdf>. Acesso em: 11 maio 2013.

BRASIL. Poder Executivo. Lei n. 284, de 28 de outubro de 1936. Diário Oficial da União. Seção 1, Suplemento, 30 out. 1936. p. 1.

BRASIL. Poder Executivo. Presidência da República. Constituição dos Estados Unidos do Brasil (10 de novembro de 1937). Rio de Janeiro, 1937. Disponível em: <http://www.planalto. gov.br/ccivil_03/constituicao/constitui\%C3\%A7ao37.htm>. Acesso em: 21 maio 2013.

BRASIL. Poder Executivo. Presidência da República. Decreto-Lei n. 579, de 30 de julho de 1938. Diário Oficial da União, Seção 1, 30 jul. 1938, p. 15168. Disponível em: <http://www2.camara.leg.br/legin/fed/declei/1930-1939/decreto-lei-579-30-julho-1938-350919publicacaooriginal-126972-pe.html>. Acesso em: 17 maio 2013.

BRASIL. Poder Executivo. Presidência da República. Decreto-Lei n. 200, de 25 de fevereiro de 1967. Diário Oficial da União, 27 fev. 1967, retificado em 17 set, 1967. Disponível em: <http://www.planalto.gov.br/ccivil_03/decreto-lei/Del0200compilado.htm. Acesso em: 4 jun. 2013.

BRASIL. Poder Executivo. Presidência da República. Decreto n. 5.378, de 23 de fevereiro de 2005. Diário Oficial da União, 24 fev. 2005. Disponível em: <http://www.planalto.gov.br/ccivil 
_03/_ato2004-2006/2005/Decreto/D5378.htm>. Acesso em: 21 maio 2013.

BRASIL. Poder Legislativo. Câmara dos Deputados. Gestão estratégica na Câmara dos Deputados. Diretriz 7 - Gestão. Disponível em: < http://www2.camara.leg.br/a-camara/gestaona-camara-dos-deputados/diretrizes-estrategicas-2012-2023/diretriz-7-gestao>. Disponível em: 22 maio 2013.

BRASIL. Poder Legislativo. Câmara dos Deputados. Resolução n. 20, de 30 de novembro de 1971. Diário do Congresso Nacional, Poder Legislativo, Brasília, DF, 1 dez. 1971.Seção 1, p. $1-39$.

BRASIL. Poder Legislativo. Câmara dos Deputados. Ato da Mesa n. 27, de 20 de agosto de 2003. Diário da Câmara dos Deputados - Suplemento - 21 ago.2003. p. 9-11.

BRESSER-PEREIRA, Luiz Carlos. Uma reforma gerencial da administração pública no Brasil. In: PETRUCCI, Vera; SCHWARZ, Letícia (org). Administração pública gerencial: a reforma de 1995 - ensaios sobre a reforma administrativa brasileira no limiar do século XXI. Brasília: UnB: ENAP, 1999. p. 17-62.

CAMPANTE, Rubens Goyatá. O Patrimonialismo em Faoro e Weber e a Sociologia Brasileira. Dados - Revista de Ciências Sociais, Rio de Janeiro, 2003. p. 153-193, v. 46, n. 1.

CARVALHO, José Murilo de. Fundamentos da política e da sociedade brasileiras. In: AVELAR, Lúcia; CINTRA, Antônio Octávio (org) Sistema Político Brasileiro: uma introdução. 2. ed. Rio de Janeiro: Fundação Konrad-Adenauer-Stiftung; São Paulo: Unesp, 2007. p. 19-31.

COSTA, Frederico Lustosa da. História das reformas administrativas no Brasil: narrativas, teorizações e representações. Revista do Serviço Público, v. 59, n. 3, jul./set. 2008. Disponível em: < http://www.enap.gov.br/index.php?option=com_docman\&task=doc_view\&gid=3176>. Acesso em: 19 maio 2013.

FAUSTO, Boris. História concisa do Brasil. 2. ed. São Paulo: Edusp, 2009.

GUIMARÃES, André Sathler et al. Gestão estratégica no Poder Legislativo: o caso da Câmara dos Deputados. Revista do Serviço Público. Brasília, jan./mar. 2012. 63, p. 25-42.

LIRA NETO, João de. Getúlio: dos anos de formação à conquista do poder (1882-1930). São Paulo: Companhia das Letras, 2012.

MINTZBERG, Henry; AHLSTRAND, Bruce; LAMPEL, Joseph. Safari de estratégia: um roteiro pela selva do planejamento estratégico. 2. ed. Porto Alegre: Bookman, 2010.

NONAKA, Ikujiro; TAKEUCHI, Hirotaka. Criação de conhecimento na empresa: como as empresas japonesas geram a dinâmica da inovação. 2 ed. Rio de Janeiro: Campus, 1997.

OLIVEIRA, José Evandro do Nascimento. O processo de implantação da gestão estratégica na câmara dos deputados: lições aprendidas pela diretoria de recursos humanos. Monografia, Centro de Formação, Treinamento e Aperfeiçoamento da

Câmara dos Deputados (Cefor), 2011. Disponível em: <http://bd.camara.gov.br/bd/handle/bdca mara/7084>. Acesso: 20 maio 2013.

PAES DE PAULA, Ana Paula. Por uma nova gestão pública: limites e potencialidades da experiência contemporânea. Rio de Janeiro: FGV, 2007.

SILVA, Leonardo Barbosa e. A reforma administrativa de 1967. In: ANDREWS, Cristina W.; 
BARIANI, Edison (org). Administração pública no Brasil: breve história política. São Paulo: Unifesp, 2010. p. 63-84.

TORRES, Marcelo Douglas de Figueiredo. Estado, democracia e administração pública no Brasil. Rio de Janeiro: FGV, 2007.

WAHRLICH, Beatriz M. de Sousa. Reforma administrativa federal brasileira: passado e presente. Rev. Adm. Pública. Rio de Janeiro, abr./jun. 1974. Disponível em:

<http://ebape.fgv.br/sites/ebape.fgv.br/files/rap5_0.pdf>. Acesso em 13 Mar. 2013.

WAHRLICH, Beatriz M. de Sousa. Reforma administrativa na era Vargas. Rio de Janeiro: FGV, 1983.

WEBER, Max. Economia e Sociedade: fundamentos da sociologia compreensiva. 4. ed. Brasília: UnB, 2012.

Artigo recebido em: 02/10/2014

Artigo aceito para publicação em: 01/12/2014 